\title{
Pengenalan Wajah Menggunakan Pembelajaran Mesin Berdasarkan Ekstraksi Fitur pada Gambar Wajah Berkualitas Rendah
}

\section{Face Recognition Using Machine Learning Based on Feature Extraction on Low Quality Face Images}

\author{
Siti Khotimatul Wildah ${ }^{1}$, Sarifah Agustiani ${ }^{1}$, Ali Mustopa ${ }^{1}$, Nanik Wuryani², Hendri \\ Mahmud Nawawi ${ }^{3}$, Rizky Ade Safitri ${ }^{4}$ \\ $1^{*}$ Program Studi Teknologi Komputer, Universitas Bina Sarana Informatika-Indonesia \\ 2 Program Studi Teknik Informatika, Sekolah Tinggi Teknologi Muhammadiyah Cileungsi-Indonesia \\ 3 Program Studi Teknik Informatika, Universitas Nusa Mandiri-Indonesia \\ 4 Program Studi Bisnis Digital, Universitas Nusa Mandiri-Indonesia \\ 1*Jl. Kramat Raya No. 98, RW. 9, Kwitang, Kec. Senen, Kota Jakarta Pusat 10450 \\ 2 Jl. Anggrek No.25 Komplek Perum PTSC, Cileungsi, Bogor, Jawa Barat-Indonesia 16820 \\ 3,4 Jl. Raya Jatiwaringin No.2, RW.13, Cipinang Melayu, Kec. Makasar, Kota Jakarta Timur 13620
}

Informasi Artikel

\section{Article History:}

Submission: 16-12-2021

Revised: 20-12-2021

Accepted: 21-12-2021

\section{Kata Kunci:}

Pengenalan wajah; Pembelajaran mesin; Ekstrasi fitur; Yale face

\section{Keywords:}

Facial recognition; Machine learning; Feature extraction; Yale face

* Korespondensi:

Siti Khotimatul Wildah siti.ska@bsi.ac.id

\begin{abstract}
Abstrak
Wajah merupakan bagian dari sistem biometric dimana wajah manusia memiliki bentuk dan karakteristik yang berbeda antara satu dengan lainnya sehingga wajah dapat dijadikan sebagai alternatif pengamanan suatu sistem. Proses pengenalan wajah didasarkan pada proses pencocokan dan perbandingan citra yang dimasukan dengan citra yang telah tersimpan di database. Akan tetapi pengenalan wajah menjadi permasalahan yang cukup menantang dikarenakan illuminasi, pose dan ekspresi wajah serta kualitas citra. Oleh sebab itu pada penelitian ini bertujuan untuk melakukan pengenalan wajah dengan menggunakan metode machine learning seperti Logistic Regression (LR), Linear Discriminant Analysis (LDA), Decision Tree Classifier, Random Forest Classifier (RF), Gaussian NB, K Neighbors Classifier (KNN) dan Support Vector Machine (SVM) dan beberapa metode ekstraksi fitur Hu-Moment, HOG dan Haralick pada dataset Yale Face. Berdasarkan pengujian yang dilakukan metode ekstraksi fitur gabungan Hu-Moment, HOG dan Haralick dengan algoritma Linear Discriminant Analysis (LDA) menghasilkan nilai akurasi tertinggi sebesar 79,71\% dibandingkan dengan metode ekstraksi fitur dan algoritma klasifikasi lainnya.
\end{abstract}

\begin{abstract}
Face is part of a biometric system where the human face has different shape and characteristics from each other so that face can be used as an alternative security system. The facial recognition process is based on the process of matching and comparing the entered image with the image that has been stored in the database. However, facial recognition is quite a challenging problem due to the illumination, poses and facial expressions as well as the quality of the imagery. Therefore, this study aims to do facial recognition using machine learning methods such as Logistic Regression (LR), Linear Discriminant Analysis (LDA), Decision Tree Classifier, Random Forest Classifier (RF), Gaussian NB, K Neighbors Classifier (KNN) and Support Vector Machine (SVM) and several hu-moment, HOG and Haralick feature extraction methods on Yale Face datasets. Based on testing conducted hu-moment, HOG and Haralick combined feature extraction
\end{abstract}


Siti Khotimatul Wildah, Sarifah Agustiani, Ali Mustopa, Nanik Wuryani, Hendri Mahmud Nawawi, Rizky Ade Safitri

Pengenalan Wajah Menggunakan Pembelajaran Mesin Berdasarkan Ekstraksi Fitur pada Gambar Wajah Berkualitas Rendah

method with Linear Discriminant Analysis (LDA) algorithm resulted in the highest accuracy value of $79.71 \%$ compared to other feature extraction methods and classification algorithm.

\section{PENDAHULUAN.}

Wajah merupakan bagian dari sistem biometrik, dimana wajah memiliki bentuk dan ciri yang berbeda-beda, sehingga perbedaan ini menjadi pengenal dan identitas setiap individu [1]. Berdasarkan ciri keunikan atau karakteristik tersebut pengenalan wajah dapat dijadikan sebagai suatu pilihan untuk pengamanan sistem dikarenakan sistem pengenalan wajah ini mampu mengidentifikasi sekaligus memverifikasi seseorang melalui citra digital maupun video [2].

Proses pengenalan wajah didasarkan pada proses pencocokan dan perbandingan citra yang dimasukan dengan citra yang telah tersimpan di database. Akan tetapi pengenalan wajah menjadi permasalahan yang cukup menantang dikarenakan illuminasi, pose dan ekspresi wajah serta kualitas citra [3]. Kualitas citra yang rendah menjadi permasalahan yang cukup penting dalam pengenalan dan identifikasi wajah. Oleh sebab itu diperlukan untuk menangani kondisi tersebut diperlukan sebuah metode atau teknik, salah satunya adalah dengan menerapkan metode computer vision.

Penelitian mengenai pengenalan dan authentifikasi wajah menggunakan metode computer vision sudah pernah dilakukan sebelumnya seperti penelitian yang pernah dilakukan mengenai Pengenalan Wajah Menggunakan metode Support Vector Machine (SVM) dengan menggunakan kombinasi dari beberapa kernel atau disebut Multi kernel [4]. Penelitian lainnya juga dilakukan mengenai Sistem pengenalan wajah berdasarkan metode lokal fitur fusion menggunakan CCA [1], kemudian penelitian yang dilakukan mengenai pengujian pengenalan wajah menggunakan metode ekstraksi fitur Linear Discriminant Analysis (LDA), Principal Component Analysis (PCA) dan Locality Preserving Projections (LPP) serta menerapkan algoritma klasifikasi k-nearest neighbor (KNN) [5]. Kemudian penelitian mengenai pengenalan wajah yang dilakukan pada tahun 2019 mengenai pengenalan wajah dengan melakukan perbandingan metode Eigenface, Fisherface, dan Local Binary Patterns Histograms (LBPH) [6]. Penelitian yang dilakukan mengenai Klasifikasi Gender Berbasis Citra Wajah dengan menggunakan ekstrasi fitur Histogram of Oriented Gradients (HOG)[7]. Tujuan dari penelitian ini adalah untuk mempelajari karakteristik berbagai data citra pria dan wanita berdasarkan ciri wajah, sehingga model klasifikasi dapat membedakan pria dan wanita melalui fitur wajah [8] mengenai sistem pengamanan rumah menggunakan ekstraksi fitur HOG dan algoritma klasifikasi KNN.

Pada penelitian ini, pengujian pengenalan wajah menggunakan dataset citra wajah Yale Face sebanyak 165 citra dengan 15 individu dan mengusulkan beberapa metode ekstraksi fitur seperti Hu Moment, HOG, dan Haralick Sedangkan algoritma klasifikasi yang digunakan diantaranya Logistic Regression (LR), Linear Discriminant Analysis (LDA), Decision Tree Classifier (CART), Random Forest Classifier (RF), Gaussian NB (NB), K Neighbors Classifier (KNN) dan Support Vector Machine (SVM). Penerapan beberapa metode ekstraksi fitur dan algoritma klasifikasi bertujuan untuk mencari metode terbaik yang dapat menghasilkan nilai akurasi yang tinggi dengan besaran error yang rendah.

\section{METODE}

Metode yang digunakan pada penelitian ini dimulai dari tahapan pemanggilan citra menggunakan Dataset Yale Face, kemudian dilakukan praproses citra, penerapan dan pengujian beberapa ekstraksi fitur. Selanjutnya dari hasil fitur ini akan dilakukan proses klasifikasi dengan menggunakan beberapa algoritma klasifikasi. Adapun langkah penelitian ini adalah sebagai berikut: 


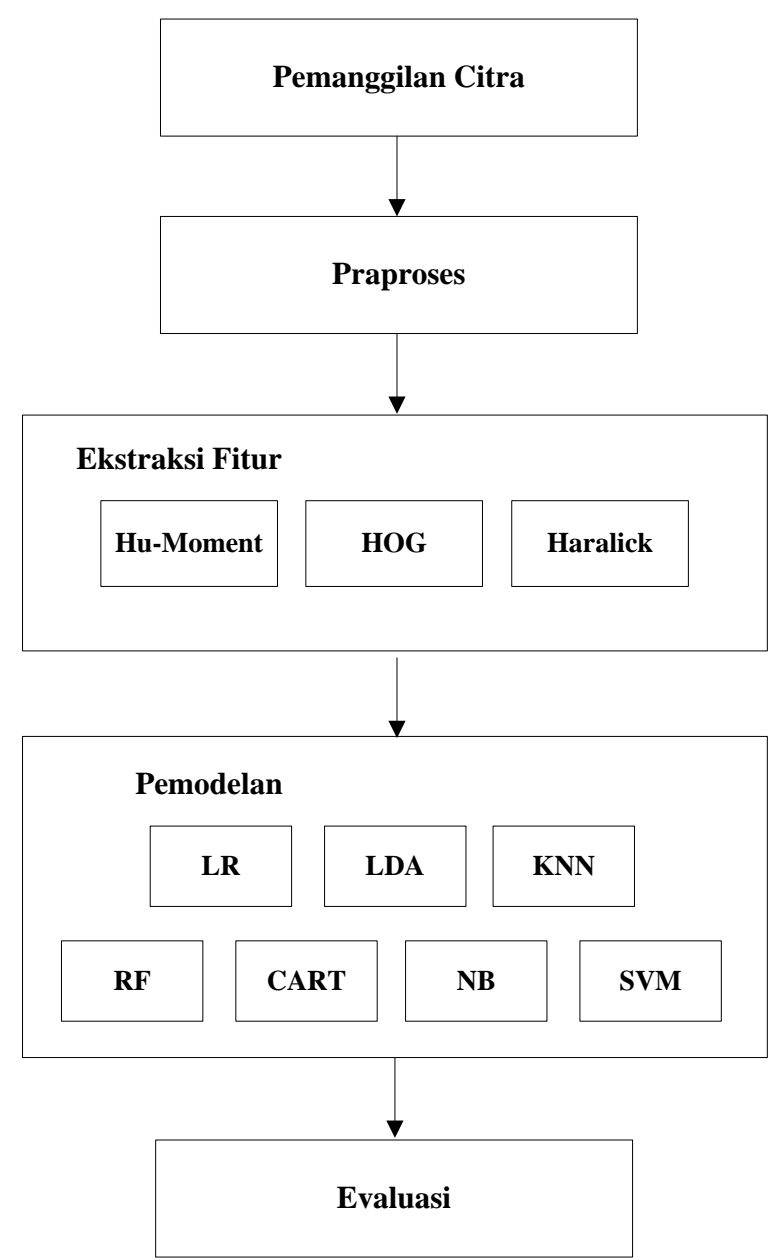

Gambar 1. Tahapan metode penelitian

\subsection{Pemanggilan citra}

Penelitian ini menggunakan Citra Yale Face Dataset yang berasal dari UCSD Computer Vision pada repository kaggle, berisi 165 citra skala abu-abu dalam format GIF dengan dimensi ukuran 100x100 pixel yang terdiri dari 15 individu, 11 citra per subjek.
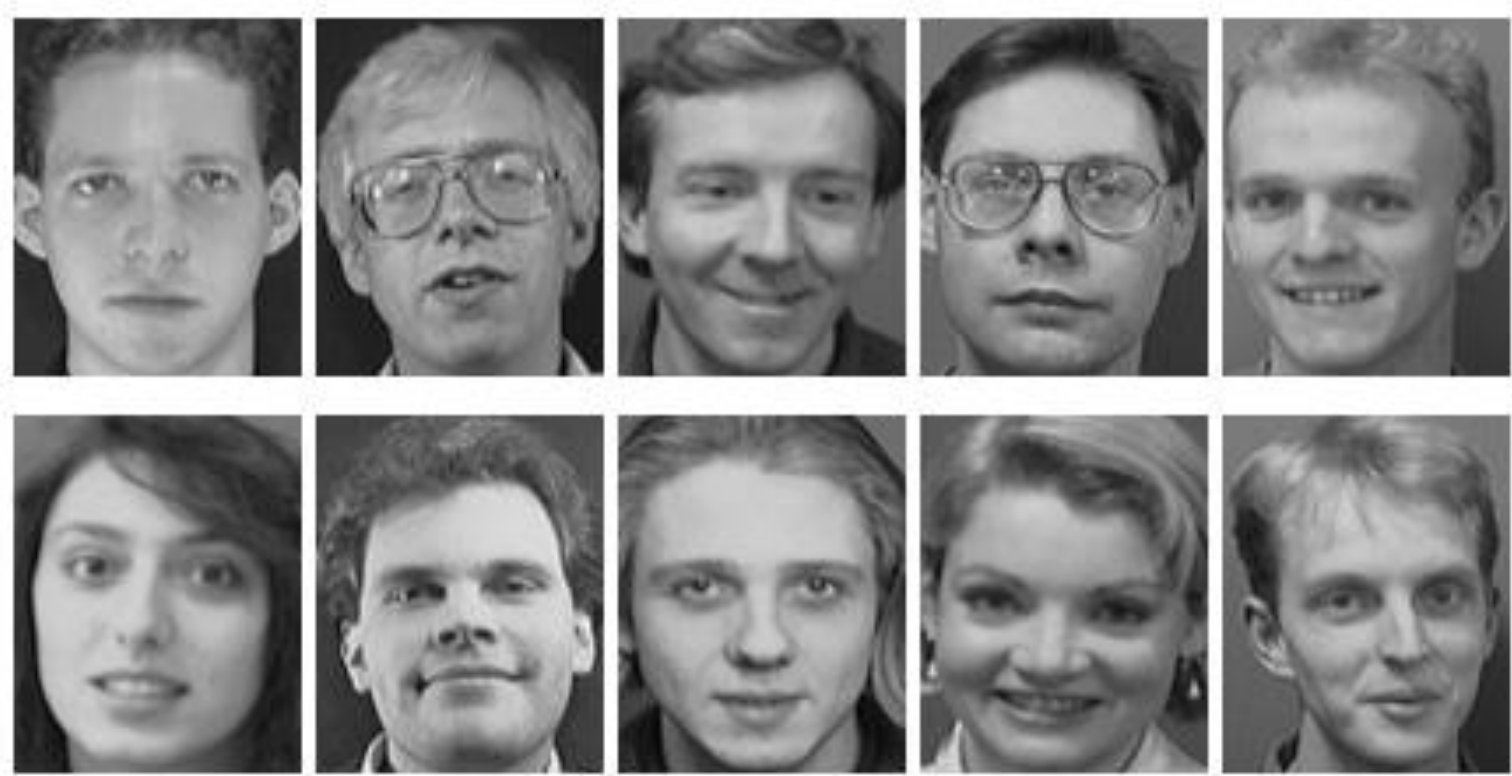

Gambar 2. Sampel citra yale face dataset 
Siti Khotimatul Wildah, Sarifah Agustiani, Ali Mustopa, Nanik Wuryani, Hendri Mahmud Nawawi, Rizky Ade Safitri

Pengenalan Wajah Menggunakan Pembelajaran Mesin Berdasarkan Ekstraksi Fitur pada Gambar Wajah Berkualitas Rendah

Berdasarkan gambar 2 dapat dilihat bahwa setiap gambar memiliki ekspresi atau konfigurasi wajah yang berbeda, seperti posisi menatap ke arah tengah, dengan menggunakan kacamata, ekspresi senang, menatap atau melihat ke arah kiri, tanpa menggunakan kacamata, normal, cahaya terang pada sebelah kanan, ekspresi sedih, mengantuk, terkejut, dan mengedipkan mata.

\subsection{Pra-pemrosesan citra}

Tahapan pra proses yang dilakukan pada penelitian ini yakni menentukan ukuran dan dimensi citra, kemudian menentukan direktori data citra uji dan data citra latih sesuai dengan kelas label yang telah ditentukan sebelum masuk ke tahap selanjutnya.

\subsection{Ekstraksi fitur}

Penelitian ini menggunakan ekstraksi fitur dengan membandingkan beberapa ekstraksi, diantaranya:

a. Hu-Moments, merupakan metode ekstraksi fitur untuk menghasilkan 7 fitur yang dapat mengidentifikasi objek. Objek yang diambil dapat berupa lokasi, area, arah, dan lain sebagainya [8].

b. Histogram of Oriented Gradients (HOG), merupakan metode ekstraksi fitur yang merepresentasikan bentuk dengan cara kerja menangkap histogram arah gradien di setiap sel yang terbagi dari sebuah citra untuk mendeteksi objek [9].

c. Haralick, adalah metode statistik yang digunakan untuk analisis objek pada citra digital dan terdiri dari 14 fitur [10].

\subsection{Pemodelan}

Penelitian ini membandingkan beberapa algoritma klasifikasi, di antaranya:

a. LR, adalah metode yang umum digunakan untuk melakukan analisis data dengan satu atau lebih variabel prediktor yang menggambarkan variabel respons. Variabel respon regresi logistik bernilai hanya 1 (ya) dan 0 (tidak), sehingga menghasilkan variabel respon Bernoulli [11].

b. LDA, merupakan metode klasifikasi konvensional dengan cara menemukan kombinasi linier dari fitur yang ada kemudian membagi sampel ke dalam kelas yang sesuai. Namun, metode ini mempunyai kekurangan yaitu tidak dapat memproses sampel data yang lebih kecil dari jumlah fitur [12].

c. KNN, merupakan metode untuk mengklasifikasikan data atau kasus baru berdasarkan kesamaan. Hal ini digunakan untuk mengklasifikasikan titik data berdasarkan klasifikasi data yang berdekatan [13].

d. RF, merupakan metode kombinasi yang didasarkan pada klasifikasi dan regresi. Metode ini bekerja dengan menghasilkan kelas klasifikasi atau prediksi regresi dalam sebuah pohon yang didapat dari pelatihan model [14].

e. Decision Tree, merupakan salah satu metode eksplorasi data, yaitu metode atau algoritma dari metode Decision Tree. CART adalah metode yang sederhana namun kuat. Karakteristik metode ini menggambarkan variabel dependen dan satu atau lebih independent variable [15].

f. Naïve Bayes, merupakan metode dengan karakteristik yang mewakili probabilitas bersyarat Kelas P (Xi | Y) serta memiliki ciri dua parameter, mean dan varians [16].

g. SVM, merupakan singkatan dari support vector machine, dimana metode ini menggunakan fungsi linier untuk membagi dua kelompok kelas data untuk menemukan ukuran maksimum sisi sudut yang terdapat dalam ruang fitur dan ruang input [17]. 


\subsection{Evaluasi model}

Pada tahapan ini dilakukan evaluasi model dari klasifikasi algoritma yang dilakukan dengan ekstraksi fitur yang digunakan untuk melihat hasil dari accuracy, precision, recall, f1-Score dan Support yang dihasilkan.

\section{HASIL DAN PEMBAHASAN}

Penelitian untuk melakukan klasifikasi pengenalan wajah ini dilakukan dengan menggunakan beberapa ekstraksi fitur di antaranya Hu-Moment, HOG, Haralick, fitur gabungan Hu-Moment dan HOG, Hu-Moment dan Haralick, HOG dan Haralick serta Hu-Moment, HOG dan Haralick. Sedangkan algoritma klasifikasi yang digunakan pada penelitian ini di antaranya LR, LDA, RF, CART, NB, SVM dan KNN.

Pengujian dilakukan dengan seluruh citra yang ada pada dataset yale face yang berjumlah 165 citra dari 15 individu, dengan dimensi 100x100 pixel. Rasio data yang digunakan pada penelitian ini sebesar 90:10 yakni 90\% data latih dan 10\% data uji. Berdasarkan pengujian tersebut diperoleh hasil sebagai berikut:

a. Hasil pengujian beberapa algoritma klasifikasi dengan ekstraksi fitur Hu-Moment

Penggunaan metode ekstraksi fitur Hu-Moment pada beberapa metode klasifikasi dengan menggunakan dataset yale face memberikan hasil yang dijelaskan pada tabel 1:

\begin{tabular}{c|l} 
Tabel 1. Pengujian fitur hu-mom \\
\hline Algoritma & Akurasi \\
\hline RF & 0.614286 \\
KNN & 0.512381 \\
CART & 0.433333 \\
LDA & 0.414286 \\
NB & 0.196667 \\
LR & 0.100952 \\
SVM & 0.000000 \\
\hline
\end{tabular}

Dari Tabel 1 penggunaan metode ekstraksi fitur Hu-Moment pada beberapa metode klasifikasi memberikan hasil bahwa metode RF menunjukan performa akurasi yang baik yakni sebesar $61,42 \%$.

b. Hasil pengujian beberapa algoritma klasifikasi dengan ekstraksi fitur HOG

Penggunaan metode ekstraksi HOG pada beberapa metode klasifikasi dengan menggunakan dataset yale face memberikan hasil sebagai berikut:

Tabel 2. Pengujian fitur HOG

\begin{tabular}{l|l}
\hline Algoritma & Akurasi \\
\hline LDA & 0.742857 \\
KNN & 0.709524 \\
RF & 0.702857 \\
NB & 0.608095 \\
CART & 0.588095 \\
LR & 0.399048 \\
SVM & 0.000000 \\
\hline
\end{tabular}



Siti Khotimatul Wildah, Sarifah Agustiani, Ali Mustopa, Nanik Wuryani, Hendri Mahmud Nawawi, Rizky Ade Safitri

Pengenalan Wajah Menggunakan Pembelajaran Mesin Berdasarkan Ekstraksi Fitur pada Gambar Wajah Berkualitas Rendah

Dari Tabel 2 penggunaan metode ekstraksi fitur HOG pada beberapa metode klasifikasi memberikan hasil bahwa metode LDA menunjukan performa akurasi yang baik yakni sebesar $74,28 \%$.

c. Hasil pengujian beberapa algoritma klasifikasi dengan ekstraksi fitur Haralick.

Penggunaan metode ekstraksi Haralick pada beberapa metode klasifikasi dengan menggunakan dataset yale face memberikan hasil sebagai berikut:

\begin{tabular}{l|l} 
Tabel 3. Pengujian fitur Haralick \\
\hline Algoritma & Akurasi \\
\hline LDA & 0.735714 \\
RF & 0.621429 \\
KNN & 0.594286 \\
CART & 0.479524 \\
NB & 0.472857 \\
LR & 0.330000 \\
SVM & 0.020476 \\
\hline
\end{tabular}

Dari Tabel 3 penggunaan metode ekstraksi fitur Haralick pada beberapa metode klasifikasi memberikan hasil bahwa metode LDA menunjukan performa akurasi yang baik yakni sebesar 73,57\%.

d. Hasil pengujian beberapa algoritma klasifikasi dengan ekstraksi fitur gabungan $\mathrm{Hu}$-Moment dan HOG.

Penggunaan metode ekstraksi Hu-Moment dan HOG pada beberapa metode klasifikasi dengan menggunakan dataset yale face memberikan hasil sebagai berikut:

Tabel 4. Pengujian fitur hu-moment dan HOG

\begin{tabular}{l|l}
\hline Algoritma & Akurasi \\
\hline LDA & 0.730000 \\
KNN & 0.729524 \\
RF & 0.723333 \\
CART & 0.546190 \\
NB & 0.486667 \\
LR & 0.439524 \\
SVM & 0.000000 \\
\hline
\end{tabular}

Dari Tabel 4 penggunaan metode ekstraksi fitur Hu-Moment dan HOG pada beberapa metode klasifikasi memberikan hasil bahwa metode LDA menunjukan performa akurasi yang baik yakni sebesar 73,00\%.

Tabel 5. Pengujian fitur hu-moment dan haralick

\begin{tabular}{l|l}
\hline Algoritma & Akurasi \\
\hline LDA & 0.783810 \\
RF & 0.695238 \\
KNN & 0.614286 \\
CART & 0.514286
\end{tabular}




\begin{tabular}{l|l} 
NB & 0.432381 \\
LR & 0.383810 \\
SVM & 0.006667 \\
\hline
\end{tabular}

e. Hasil pengujian beberapa algoritma klasifikasi dengan ekstraksi fitur gabungan $\mathrm{Hu-Moment}$ dan Haralick.

Penggunaan metode ekstraksi Hu-Moment dan Haralick pada beberapa metode klasifikasi dengan menggunakan dataset yale face memberikan hasil sesuai tabel 5. Dari Tabel 5 penggunaan metode ekstraksi fitur Hu-Moment dan Haralick pada beberapa metode klasifikasi memberikan hasil bahwa metode LDA menunjukan performa akurasi yang baik yakni sebesar 78,38\%.

f. Hasil pengujian beberapa algoritma klasifikasi dengan ekstraksi fitur gabungan HOG dan Haralick.

Penggunaan metode ekstraksi HOG dan Haralick pada beberapa metode klasifikasi dengan menggunakan dataset yale face memberikan hasil sebagai berikut:

Tabel 6. Pengujian fitur HOG dan Haralick

\begin{tabular}{l|l}
\hline Algoritma & Akurasi \\
\hline LDA & 0.785238 \\
RF & 0.689524 \\
KNN & 0.689048 \\
CART & 0.600952 \\
NB & 0.595238 \\
LR & 0.540000 \\
SVM & 0.000000 \\
\hline
\end{tabular}

Dari Tabel 6 penggunaan metode ekstraksi fitur HOG dan Haralick pada beberapa metode klasifikasi memberikan hasil bahwa metode LDA menunjukan performa akurasi yang baik yakni sebesar 78,53\%.

g. Hasil pengujian beberapa algoritma klasifikasi dengan ekstraksi fitur gabungan Hu-Moment, HOG dan Haralick.

Penggunaan metode ekstraksi fitur gabungan Hu-Moment, HOG dan Haralick pada beberapa metode klasifikasi dengan menggunakan dataset yale face memberikan hasil pada tabel 7.

Tabel 7. Pengujian fitur Hu-Moment, HOG dan Haralick

\begin{tabular}{ll}
\hline Algoritma & Akurasi \\
\hline LDA & 0.797143 \\
RF & 0.716190 \\
KNN & 0.695238 \\
CART & 0.600476 \\
LR & 0.573810 \\
NB & 0.520476 \\
SVM & 0.000000 \\
\hline
\end{tabular}

Dari Tabel 7 penggunaan metode ekstraksi fitur HOG dan Haralick pada beberapa metode klasifikasi memberikan hasil bahwa metode LDA menunjukan performa akurasi yang baik yakni sebesar $79,71 \%$. 
Pengenalan Wajah Menggunakan Pembelajaran Mesin Berdasarkan Ekstraksi Fitur pada Gambar Wajah Berkualitas Rendah

Berdasarkan hasil pada tabel 7 dapat dijelaskan bahwa nilai akurasi tertinggi diperoleh pada penerapan algoritma klasifikasi LDA dengan ekstraksi fitur gabungan antara Hu-Moment, HOG dan Haralick serta secara keseluruhan pada beberapa pengujian algoritma LDA memberikan hasil yang cukup tinggi dibandingkan dengan algoritma klasifikasi lainnya. Hal ini menunjukan bahwa penerapan algoritma LDA dan ekstraksi fitur gabungan antara Hu-Moment, HOG dan Haralick merupakan metode yang baik dalam pengenalan wajah. Eksperimen ini juga menghasilkan beberapa nilai laporan klasifikasi seperti nilai precision, recall, f1-score, dan support yang dapat dilihat pada gambar berikut:

Tabel 8. Classification report LDA dan fitur gabungan Hu-Moment, HOG dan Haralick

\begin{tabular}{lllll}
\hline \multicolumn{1}{c}{ Precision } & Recall & F1-Score & Support & \\
\hline 0 & 1.00 & 1.00 & 1.00 & 3 \\
1 & 0.67 & 0.67 & 0.67 & 3 \\
2 & 0.50 & 0.67 & 0.57 & 3 \\
3 & 0.00 & 0.00 & 0.00 & 6 \\
4 & 0.40 & 0.67 & 0.50 & 3 \\
5 & 0.60 & 1.00 & 0.75 & 3 \\
6 & 0.50 & 0.67 & 0.57 & 3 \\
7 & 1.00 & 0.33 & 0.50 & 3 \\
8 & 0.67 & 0.67 & 0.67 & 3 \\
9 & 1.00 & 0.50 & 0.67 & 4 \\
10 & 0.50 & 1.00 & 0.67 & 3 \\
11 & 0.29 & 0.67 & 0.40 & 3 \\
12 & 1.00 & 0.67 & 0.80 & 6 \\
13 & 1.00 & 0.50 & 0.67 & 2 \\
14 & 0.00 & 0.00 & 0.00 & 1 \\
Micro Avg & 0.59 & 0.59 & 0.59 & 49 \\
Macro Avg & 0.61 & 0.60 & 0.56 & 49 \\
Weighted Avg & 0.62 & 0.59 & 0.56 & 49 \\
\hline
\end{tabular}

\section{SIMPULAN}

Berdasarkan pengujian yang telah dilakukan dalam pengenalan wajah menggunakan dataset citra Yale Face dapat disimpulkan bahwa penerapan algoritma klasifikasi dan ekstraksi fitur yang baik dihasilkan dengan penerapan ekstraksi fitur gabungan Hu-Moment, HOG dan Haralick terhadap algoritma LDA dengan nilai akurasi yang dihasilkan sebesar 79,71\%. Selain itu, LDA juga menghasilkan nilai akurasi yang cukup tinggi pada beberapa pengujian dibandingkan dengan algoritma klasifikasi lainnya. Penerapan ekstraksi fitur memiliki pengaruh terhadap penelitian pengenalan wajah ini dan fitur gabungan menghasilkan nilai akurasi yang lebih besar dibandingkan dengan pengujian yang hanya menggunakan satu fitur ekstraksi. Hasil yang diperoleh pada penelitian ini belum terlalu tinggi, maka pada penelitian selanjutnya disarankan untuk menggunakan metode Deep Learning

\section{DAFTAR PUSTAKA}

[1] M. Athoillah, U. Pgri, A. Buana, J. Ngagel, D. I. No, And K. Surabaya, "Pengenalan Wajah Menggunakan Svm Multi Kernel Dengan Pembelajaran Yang Bertambah,” Vol. 2, No. 2, Pp. 84-91, 2017, Doi: 10.15575/Join.V2i2.109.

[2] Q. Mutiara And E. Prasetyo, “Lbph Pada Sistem Pengenalan Wajah,” Vol. 18, 2019. 
[3] E. Zangeneh, M. Rahmati, And Y. Mohsenzadeh, "Low Resolution Face Recognition Using A Two-Branch Deep Convolutional Neural Network Architecture," Expert Syst. Appl., P. 112854, 2019, Doi: 10.1016/J.Eswa.2019.112854.

[4] M. Z. N. Al-Dabagh, M. I. Ahmad, M. N. Isa, And S. A. Anwar, "Face Recognition System Based On Fusion Features Of Local Methods Using Cca," 2020, Doi: 10.1109/Ieecon48109.2020.229489.

[5] E. Setiawan And U. Kasma, "Pengujian Pengenalan Wajah Dengan Menggunakan Algoritma K-Nearest Neighbor,” No. 372, Pp. 52-62.

[6] D. Devito, R. C. Wihandika, And A. W. Widodo, "Ekstraksi Ciri Untuk Klasifikasi Gender Berbasis Citra Wajah Menggunakan Metode Histogram Of Oriented Gradients," Vol. 3, No. 8, Pp. 8002-8011, 2019.

[7] B. Septian, A. Wijayanto, F. Utaminingrum, And I. Arwani, "Face Recognition Untuk Sistem Pengaman Rumah Menggunakan Metode Hog Dan Knn Berbasis Embedded,” Vol. 3, No. 3, Pp. 2774-2781, 2019.

[8] H. Y. Susetya, A. Rachmat, And K. A. Nugraha, "Implementasi Moment Invariant Untuk Pengenalan Label Buku Perpustakaan Berbasis Android," J. Terap. Teknol. Inf., Vol. 1, No. 1, Pp. 21-30, 2017, Doi: 10.21460/Jutei.2017.11.13.

[9] Y. Yohannes, M. R. Pribadi, And L. Chandra, "Klasifikasi Jenis Buah Dan Sayuran Menggunakan Svm Dengan Fitur Saliency-Hog Dan Color Moments," Elkha, Vol. 12, No. 2, P. 125, 2020, Doi: 10.26418/Elkha.V12i2.42160.

[10] Suryanto And E. Dodi, "Ekstraksi Fitur Haralick Menggunakan Citra Mikroskop Digital Trinocular Untuk Proses Identifikasi Cacing Penyakit Kaki Gajah,” No. July, 2015.

[11] A. Bimantara And T. A. Dina, "Klasifikasi Web Berbahaya Menggunakan Metode Logistic Regression," Annu. Res. Semin., Vol. 4, No. 1, Pp. 173-177, 2019.

[12] W. Astuti And A. Adiwijaya, "Principal Component Analysis Sebagai Ekstraksi Fitur Data Microarray Untuk Deteksi Kanker Berbasis Linear Discriminant Analysis," J. Media Inform. Budidarma, Vol. 3, No. 2, P. 72, 2019, Doi: 10.30865/Mib.V3i2.1161.

[13] L. Qoiriyah, H. L. Purwanto, And W. Setiyaningsih, "Rancang Bangun Sistem Pendukung Keputusan Penentuan Jenis Beasiswa Menggunakan Knn," J. Terap. Sains Teknol. Fak., Vol. 1, No. 2, Pp. 64-72, 2019.

[14] E. Y. S. Ritno, N. A. Hasibuan, And Fadlina, "Implementasialgoritma Clasification Andregression Trees ( Cart ) Dalam Klasifikasi Ekonomi Keluarga Pada Desadagang Kelambir Tg . Morawa," Maj. Ilm. Inti, Vol. 6, No. 1, Pp. 66-72, 2018.

[15] A. R. Muslikh, H. A. Santoso, And A. Marjuni, "Klasifikasi Data Time Series Arus Lalu Lintas Jangka Pendek Menggunakan Algoritma Adaboost Dengan Random Forest," J. Teknol. Inf., Vol. 14, No. 1, Pp. 24-38, 2018.

[16] B. Kurniawan, M. A. Fauzi, And A. W. Widodo, "Klasifikasi Berita Twitter Menggunakan Metode Improved Naïve Bayes," J. Pengemb. Teknol. Inf. Dan Ilmu Komput. Univ. Brawijaya, Vol. 1, No. 10, Pp. 1193-1200, 2017.

[17] D. Alita, Y. Fernando, And H. Sulistiani, "Implementasi Algoritma Multiclass Svm Pada Opini Publik Berbahasa Indonesia Di Twitter," J. Teknokompak, Vol. 14, No. 2, P. 86, 2020. 